extended much beyond this. In collaboration with Dr S.B.G. Eysenck, they looked at the personality traits characteristic of all their thousands of subjects and found that these were related to the position of the planets in a meaningful and predictable fashion. They found very highly significant relations between the positions of the planets at the birth of a child, and those at the birth of his parents. They found that these relations obtain only when the birth was natural, but vanish when the birth was induced. This is not the place to give a complete description of all the Gauquelins' later work, but it very much reduces the value of The Gemini Syndrome that it fails abysmally to go into details about these experiments, that it does not mention more than a small part of them, and that it makes criticisms which are quite erroneous in the light of later developments. In view of the fact that the research of the Gauquelins is now recognized as the major positive support for astrology, the authors of a book such as this should have been especially careful to make sure to discuss it in detail; and if they were unwilling to agree with my own estimate of the value of these studies, they should have provided detailed criticisms which, if incorrect, could be refuted. Their failure to do so makes the book unacceptable as "a scientific evaluation of astrology", to quote the subtitle - a scientific evaluation does not leave out almost entirely evidence on one side of a question, while dwelling exclusively on that favouring the other side.

The work of the Gauquelins does not make astrology a science, but it does suggest that there are factual observations embedded in the mass of nonsense, and that it may be a legitimate task for science to dig them out and try to explain them. The extreme prejudice with which the Gauquelins' results were treated by many scientists does not constitute a good advertisement for the objectivity that scientists are supposed to manifest, and the way Culver and Ianna deal with the topic is unlikely to restore one's faith.

H.J. Eysenck is Professor of Psychology Emeritus at the Institute of Psychiatry, University of London.

\section{Behind the cue and the complex}

\section{Stuart Sutherland}

The Hans Legacy: A Story of Science. By Dodge Fernald.

Lawrence Erlbaum: 1984. Pp.241. Hbk $\$ 29.95$, f22.95; pbk \$19.95.

Clever Hans and Little Hans both achieved celebrity in the early years of this century. One was a horse whose feats included reading, arithmetic and telling the time. The other was a small boy who developed a fear of horses and who was analysed by Freud: his case plays an important role in the history of psychoanalysis because it was thought to provide some of the most striking evidence for the Oedipus complex. In The Hans Legacy Dodge Fernald retells the two stories on the pretext that they both illustrate the application of the scientific method.

Fernald's account of Clever Hans is of considerable interest, since the story has not been told in such detail in recent years. The wily horse's pretensions were exposed by Oskar Pfungst, a graduate student in psychology. Hans's owner, an honest man, had trained him to reply to questions by tapping out the correct number with his foot. In an investigation of great thoroughness, Pfungst showed than when the right number was reached people in the audience tended to raise their heads slightly and that Hans used this movement as a cue to stop tapping. His replies were random when he could not see anyone, while if Pfungst himself deliberately raised his head after the wrong number of taps, Hans made the corresponding mistake.

Much has been written about the other Hans, but regrettably Fernald does not cite one of the most important articles, that by Joseph Wolpe and Stanley Rachman who debunk Freud's claim that Little Hans's phobia provides evidence for the existence of the Oedipus complex. Little Hans himself claimed that his phobia stemmed from seeing a horse fall down in the street, a terrifying experience for a small boy. In fact, Freud only saw his patient once during the analysis most of which was conducted at one remove by Hans's father, himself an ardent disciple of Freud's.

The father appears to have set out to convince the poor child that he had an Oedipus complex. Hans at first resisted suggestions that horses were a symbol for his father, and that he feared his father and wanted to supplant him in his relationship with his mother, but being a well-mannered and obedient lad he eventually gave a reluctant assent. Although Fernald brings out some of the ways in which Freud and the father misused the evidence, he does not reveal the extent to which they deceived themselves and insists on regarding the analysis as an example of the scientific method. If the cases of Clever Hans and Little Hans have anything in common, it is that both the horse and the boy were trained to respond in a certain way and that their trainers - Clever Hans's owner and Freud respectively - then proceeded to misinterpret the effects of the training.

Fernald frequently digresses. For example, he gives a brief but informative account of $\mathrm{N}$-rays in whose existence French scientists believed for a time. The two main stories and the digressions are, however, more interesting than the lessons about scientific method that Fernald is determined to draw. He breaks up both investigations into the formation, testing and verification of hypotheses and he discusses the preparation of scientific reports, using as examples those written by Pfungst and Freud. Pfungst obligingly conformed to the standard format - "Introduction, methods, results, discussion"; Freud did not. Fernald's account of scientific method seems jejune, so much so that it is unclear at whom the book is aimed. No hints are given of the role of serendipity or hunch in science. He discusses scientific fame, but fails to acknowledge that it is often achieved not by those who discover important truths or who build interesting theories, but by those who make the most noise.

Stuart Sutherland is Director of the Centre for Research on Perception and Cognition. University of Sussex.

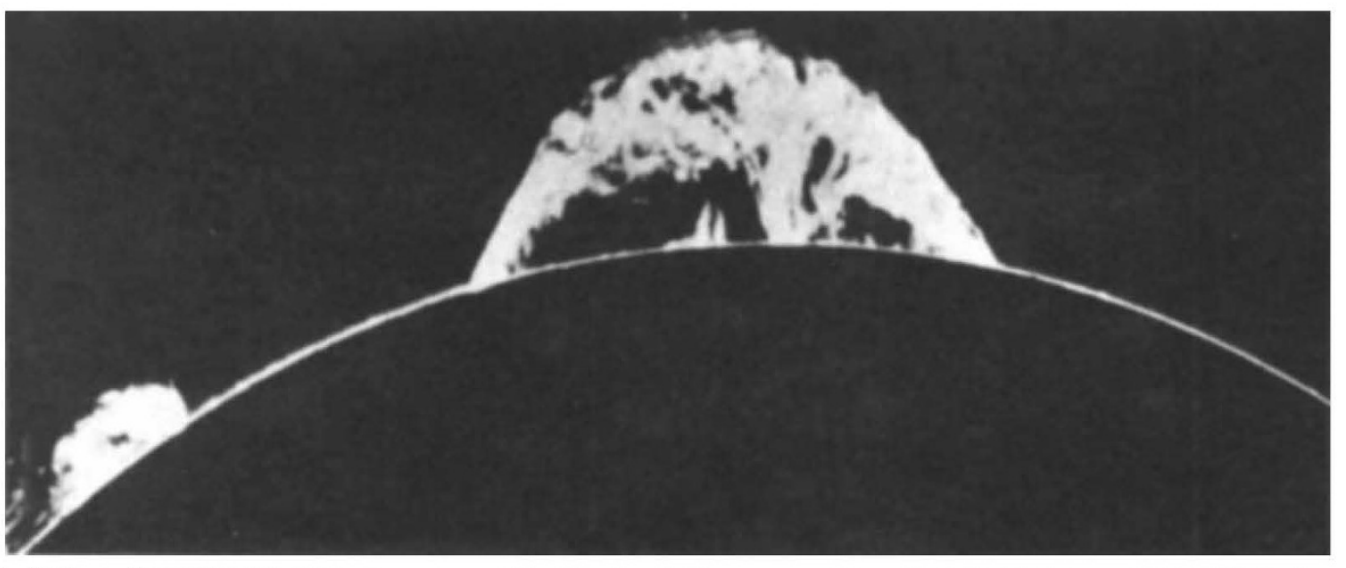

Splendid outburst - the photograph, of a prominence on the limb of the Sun, is reproduced from Secrets of the Sun by Ronald Giovanelli.

The book is a highly illustrated account of the Sun and solar phenomena, and is published by Cambridge University Press (price $£ 11.95$, \$19.95). 